\title{
Challenges for Connecting Citizens and Smart Cities: ICT, E-Governance and Blockchain
}

\author{
Thays A. Oliveira ${ }^{1} * \mathbb{D}$, Miquel Oliver ${ }^{1}(\mathbb{D})$ and Helena Ramalhinho ${ }^{2} \mathbb{D}$ \\ 1 Department of Information and Communication Technologies, Universitat Pompeu Fabra, \\ Edifici Tànger, 122-140, 08018 Barcelona, Spain; miquel.oliver@upf.edu \\ 2 Department of Economics and Business, Universitat Pompeu Fabra, Carrer de Ramon Trias Fargas, 25-27, \\ 08005 Barcelona, Spain; helena.ramalhinho@upf.edu \\ * Correspondence: thaysaparecida.deoliveira01@estudiant.upf.edu or thaysoliveira7@gmail.com
}

Received:12 February 2020; Accepted: 27 March 2020; Published: 7 April 2020

\begin{abstract}
The way citizens interact with cities affects overall life quality. Their participation in social decisions is of paramount importance for helping on public decisions that affect governance, regulation and education. This interaction has the potential of being boosted within the scope of smart and digital cities, especially by recent advances in blockchain technology. This work introduces insights about how smart cities' concepts and innovative technologies can help society to face daily challenges for improving citizens' awareness. Digital technologies are able to drive social and economic development by employing Information and Communication Technology (ICT) to promote innovation. In this context, e-governance, in conjunction with disruptive concepts such as blockchain, is showing up as a fundamental tool for a decentralized democracy. This study reviews, discusses, raises open points and presents suggestions towards an efficient, transparent and sustainable use of technology, applied to future cities.
\end{abstract}

Keywords: smart cities; digital cities; citizens; blockchain; ICT; e-governance; sustainability; urban planning; green technologies; smart contracts

Key Contribution: Highlights the state of the art and trends in citizens relationship with smart and digital cities. This study presents an overview of the evolution of the term smart cities, connecting it with the use of ICT and the potential brought by blockchain and other emerging technologies.

\section{Introduction}

The population has been increasing around the world and, along with this growth, new strategies are being planned to provide a better life for humankind. New initiatives and novel technologies are emerging in various manners, promoting a new wave of innovation within cities' services. However, even with continuous advance of cities and digital technologies, different challenges to engage citizens in social decisions are still open and need to be faced [1]. Information and Communication Technology (ICT) has the potential to improve this relationship with the transformation of cities' systems into decentralized and didactic tools [2]. In this context, e-governance emerges as a fundamental tool and as the first step of this transformation [3].

The concept "Smart City" (SC) was introduced in the 1990s, opening perspectives on how recent technology could affect cities. Dameri and Cocchia (2013) [4] presented an overview on the history of the label "smart", pointing out that the first study that conceptualized SC was in 1992 by Gibson et al. [5], entitled The Technopolis Phenomenon: Smart Cities, Fast Systems, Global Networks. Next, SC in connection with ICT and urban evolution started to walk side by side, as can be verified in the works of Graham (1996) [6] and Graham and Marvin (1997) [7]. It can be affirmed that the SC concept is 20 years old and it is in continuous progress [8]. The SC main objective would be 
to facilitate the planning, construction and intelligent services of the cities; however, it has been highlighted [4,9-12] that this concept may be becoming so skeptical and futuristic that is being called "smart utopia" [8]. The work of Barbosa et al. (2019) [13] highlights a path for sustainable digital transformation, pointing out some of these concepts and several complexities introduced when modern technologies are in the urban sphere. Sadin (2013) [14] commented on the drawbacks from the accumulation of power of those who manage a high volume of data, which would be the case of smart cities. However, as we emphasize within this study, blockchain and decentralized technologies, such as the use of renewables, enlighten the path for decision making distribution throughout classical means of democracy. In essence, SCs should provide a new view about cities, emphasizing the citizens, which are the most important part of it. Following this reasoning, one of the main goals of these cities should be to make the urban environment more integrated with citizens. More than that, SCs should provide more participative decision-making processes, more sensible and with transparency, inside and outside the government. When we mention transparency, it is worth noting the book of Byung-Chul Han (2015) [15], known as "Society of Transparency", which highlights the difference between trust and exposure. While trust is a quality that is the core of human relationships, transparency has some dual interpretations. Transparency may be becoming a need that extrapolates the trust of the involved stakeholders. Following this reasoning, we carefully point out blockchain as a path of trust and not only a path of transparency. While transparency is not the focus, the main goal is to create networks of trust, in which exchange of information and assets are done in optional transparent manners.

E-governance encompasses how to govern, serve, organize and formulate proposals related to worldwide communities that are settled on urban areas. It works in order to develop technologies to promote citizens' participation in different areas, which has been getting attention in the last decade [16] due to its impact on life quality [17]. This concept also intersects with Civic Tech [18]. Aligned with this, blockchain technology has also recently emerged as a fundamental platform for providing trust and auditable data, through a decentralized peer-to-peer network using cryptographic techniques [19]. It provides the users capabilities of performing decentralized exchange of values/assets in trusted networks, giving birth to the Internet of Value (IoV) [20]. We believe that this is still a rather new concept, with many implications on the next generation protocols and uses by citizens [21].

Some technologies can help to connect smart cities' citizens with city services and tools. As an example of key areas we could highlight: Transportation (smart mobility), politics, governance, education, public transparency and citizens' rights, among others. Infrastructure provides citizens the ability of free choice over the best way to come and go. In another possible view, as briefly mentioned by the European Union Agency for Network and Information Security [22], "Smart Cities rely on an ICT architecture to retrieve, process and exchange data (p. 06)". They mention data exchange because there are different kinds of cities and management policies; however, common data can be used within them. All these areas and concepts work much better when connected, interconnected and promoting participative actions. These are relevant issues for both developed and underdeveloped countries [23]. Technology comes as a tool to facilitate these points with the government.

The research questions focused on in this study are:

- What are the challenges that cities have been facing for improving citizens' life quality?

- Has the smart city concept been explored in order to understand how it can benefit citizens?

- Did works from the literature cover awareness of citizens in relation to emerging technologies?

In order to achieve the desired goal proposed within the scope of this paper, emerging technologies that benefit citizens over the ongoing societal transformation process will be discussed in this study. Based on state-of-the-art available tools and promising ideas, this work focuses on presenting innovative views and trends. The proposed methodology of this research is based on:

- Providing a decent background to smart cities and their importance for boosting societal transformation: 
- Authors being motivated by the innovation brought with the SC concept, which has been motivating governmental discussions, conferences, forums and different incentives for the industry;

- Thus, this paper highlights an overview of its history and trends.

- Conducting a bibliometrics study in order to identify gaps and trends;

- Connecting the numerical findings with authors' backgrounds obtained from conferences, workshops, roundtables and special sessions organized between 2016 and 2020 [24] in order to obtain key directions to be explored in this study;

- Explore the obtained topics and propose cutting edge solutions using those main keywords selected by the authors (which are ICT, e-governance and blockchain).

In summary, some of the contributions of this work are:

- Present an overview and trends on smart cities;

- Discuss some challenges regarding the relationship of citizens and cities;

- Discuss governance and its contributions for an effective citizens' integration; in particular, throughout decentralized technologies such as blockchain;

- Introduce possibilities, emerging governance models and possible problems that can still be solved.

The remainder of this paper is organized as follows. Section 2 presents an overview of smart cities and academic motivation to investigate this concept. Based on studies from the literature and data obtained from bibliometrics, the authors identified key points to approach technology and citizens, which are introduced in Section 3. That section presents the role of ICT in solving cities' challenges, including discussions about emerging technologies such as blockchain and other trends for innovation and e-governance. Finally, Section 4 concludes the work.

\section{Understanding Smart Cities' Importance}

Along with fast urban growth comes new confrontations, so cities' transformation plays a fundamental role in facing new barriers, resolving urban problems and improving life quality [25]. Sassen (2004) [26] use the global city term to refer to cities as an important point of financial and producer services that makes the globalized economy run. According to Sun et al. (2016) [27], the world's population will double by 2050 . This fortifies and motivates SC studies around the world in order to create more comfortable and harmonious urban spaces. The potential for motivating cities' transformation and novel initiatives is noble since this topic urges discussions from different spheres. In order to define the terms smart city and sustainable city, Ahvenniemi et al. (2010) [12] used 16 city assessment frameworks, eight for each term. A total of 958 indicators were divided by three impact categories (economic, social and environmental) and 12 sectors. They defined that: "Sustainability assessment should be part of the SC development and therefore we find it important to integrate sustainability and smart city frameworks, so that both views are accounted for in performance measurement systems" [12]. Finally, it was recommended to use the term "smart sustainable cities" instead of "smart cities", indicating that metrics for assessment of a smart city should also consider environmental, economic and social sustainability aspects. Yao et al. (2008) [28] advocate that smart cities are more ecologically efficient, with a significant positive and increasing impact over time.

Some of the global standard organizations have been dealing with the smart cities concept such as the International Standards Organization; British Standards Institute; International Telecommunications Union; International Electronical Commission and the American National Standards Organizations. According to these standards, SC is a new concept and city model that involves a new generation of ICT and Internet of Things (IoT), defining it (p. 02) [29] as follows:

"Smart Cities: a new concept and new model, which applies the new generation of information and communication technologies such as the Internet of things, cloud computing, 
big data and space/geographical information integration, to facilitate the planning, construction, management and smart services of cities."

In 1998, Bollier [30] proposed new political practices to improve urban planning [31] and used the smart growth term. This reaffirms that the SC concept originated from different ideas and scenarios. Dameri and Cocchia (2013) [4] defended SC as the search for solutions for cyber-physical integration in urban space, with the main objective to promote sustainable development of the cities; the SC tend to open new innovations possibilities in diversified areas, like health, welfare, energetic efficiency and transport [27,32]. Zhuadar et al. (2017) [33] conducted a study focused on the next wave of innovation, which combines humans' ability to connect to machines. The studied example is from the IBM Intelligent Operation Center, a so-called "system of systems", which was advocated to improve life quality by integrating data to cities' authorities. The authors concluded that the innovation came from humans' ability to connect to machines and the data obtained from these connections. Modern cities have a great potential to interact between each other in a smooth manner $[34,35]$. The old empires and former countries of our modern world have always been passing through changes; nowadays, with the recent globalization of communication, we are able to ponder citizens' perspectives [36,37]. Recently, in 2020, Chamoso et al. [38] highlighted that the design and development of platforms for big data processing should be a priority, with focus on citizen-oriented management. As described by Batty (2013):

"I describe how the growth of big data is shifting the emphasis from longer term strategic planning to short-term thinking about how cities function and can be managed, although with the possibility that over much longer periods of time, this kind of big data will become a source for information about every time horizon." [39] (p. 274).

One of the main motivations for conducting this study is due to the SC relevant concepts and actual focus that it has been receiving by the government and the industrial sector. In an effort to emphasize the wide spread adoption of these concepts, Figure 1 shows the trends from searching the term "smart city" in different languages, with data obtained from Google Trends (which process around 30 million searches per week [39]), a tool that allows the use of data from 2004 and is commonly used to evaluate the popularity of certain keywords.

Interesting patterns can be seen in each of these graphs. Such trends can be related to distinct factors, such as specific funding schemes and policies. For instance, a growing trend on the topic can be seen with searches done in English and Korean, as well as Russian. Portuguese speaking countries have been also showing an upwards tendency. The search with Chinese terms has peaks spread during the period, which provides a clue that there are hypes and cycles in which the topic attracts more interest. The tendency with searchers in French is stable, which emphasizes that the topic has been viewed and researched constantly. For Arabic and Polish, the conclusions are less relevant; however, there can be noticed a growing interest right now (from 11/2019 to 02/2020) with searchers in Polish.

Figure 2 was elaborated in order to illustrate some of these topics and areas possibly covered by a SC, representing its advantages for the citizens. As it is possible to see that the citizens are located in the center circle; this is to represent how important they are in consideration with the services offered to them. The second circle represents items commonly considered in different areas in an SC. These items items can be generalized for all these four exemplified covered areas. The last part composed by the smaller circles exemplifies applications and possible technologies for each area, connecting them with the potential brought by emerging technologies. Following this reasoning, the main idea is to connect different operations and services in favor of improving citizens' lives, in particular, by improving these major cities' strategic fields. 

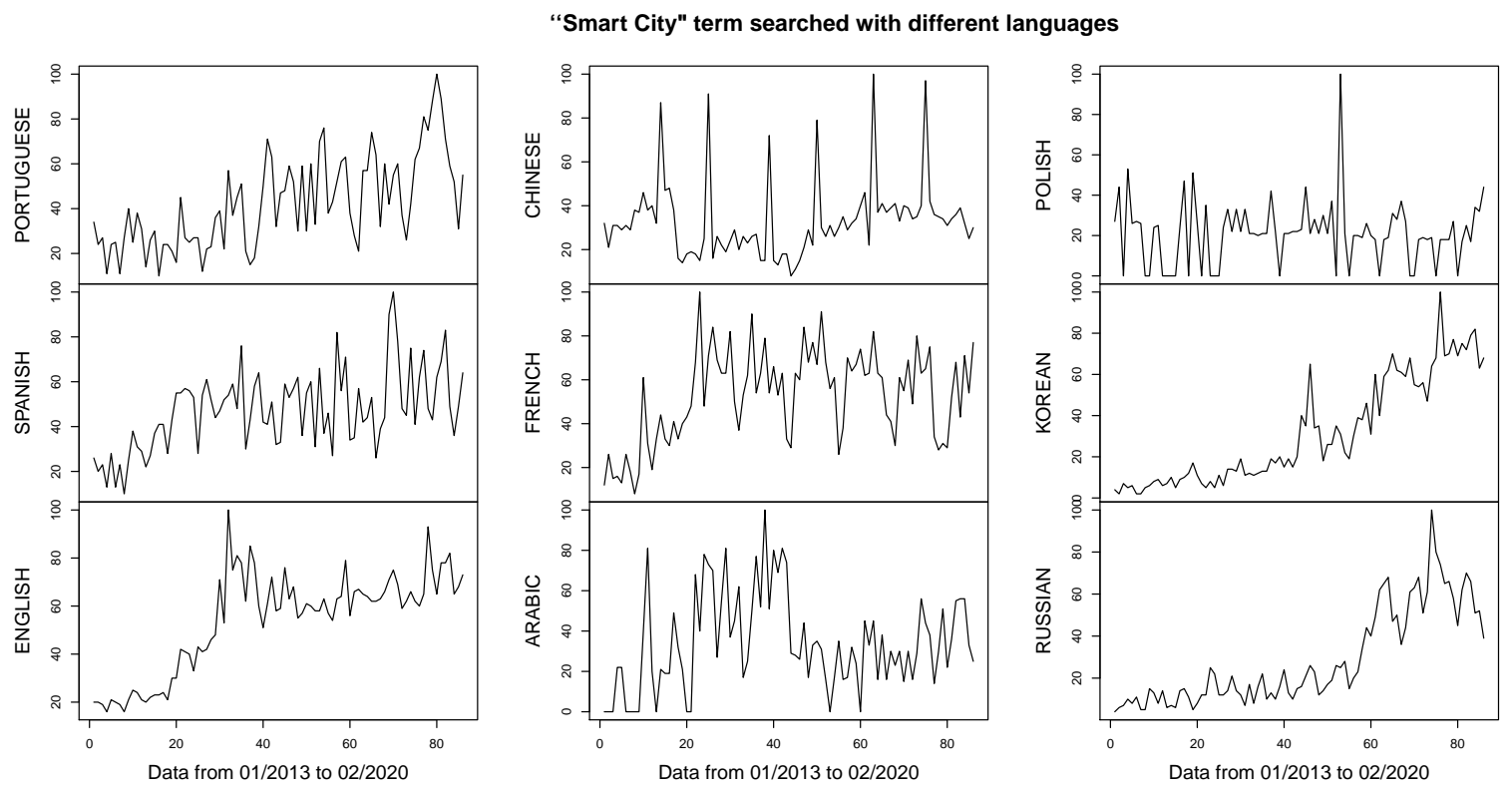

Figure 1. Google Trends search with the term "smart city" in different languages.

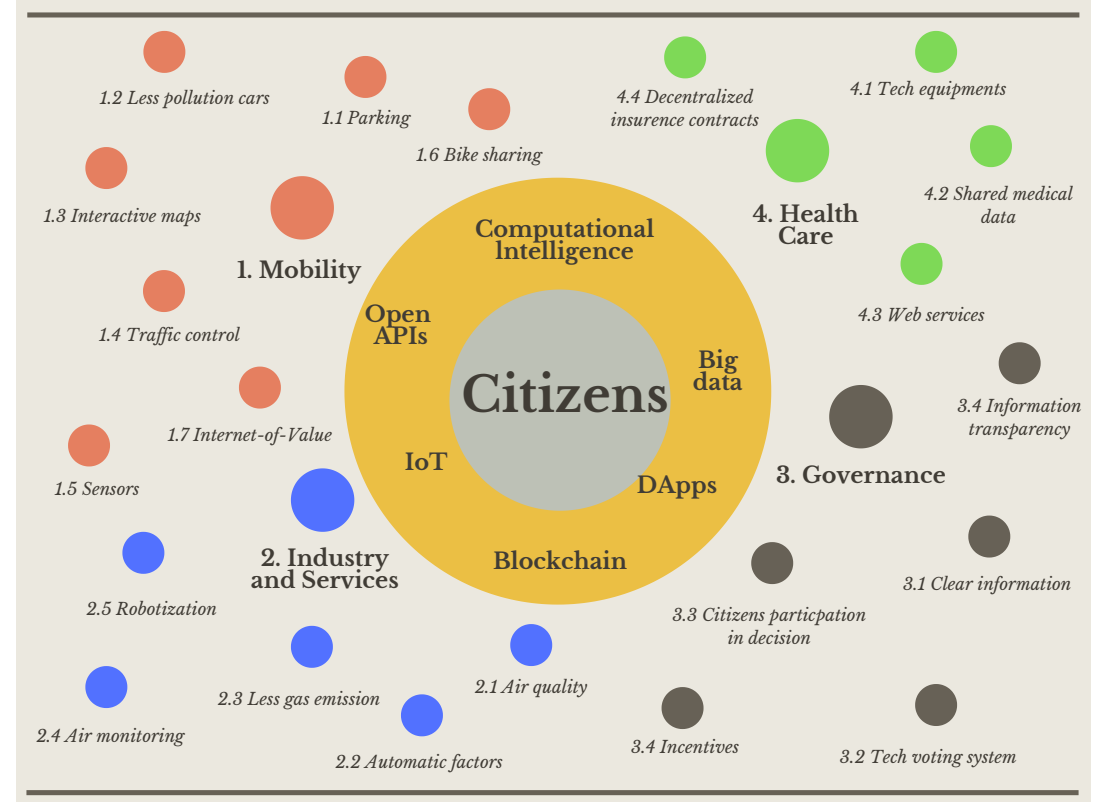

Figure 2. Some areas of expertise and topics covered in the scope of smart cities. Blockchain can be seen as a potential trend.

The success of SC is linked to the connection between strategic areas, as can be verified in the bibliometric search that was conducted. During the organization of workshops, conferences and round-tables surrounding the topic of digital and smart cities, the authors conducted brainstorming sessions for selecting keywords to be investigated (some of them were considered in sets). In this sense, any combination of at least one term in the set with smart city (or smart cities) was considered. The procedure was conducted using generic logic expressions, which were inserted into different global reference databases: Web of Science [40], SCOPUS [41] and IEEEXplore [42]. The following sets of keywords were searched: 
1. Smart city or smart cities (namely SC, for simplicity);

2. $\mathrm{SC}+($ Operations Research or Operational Research);

3. $\mathrm{SC}+$ Citizens;

4. $\mathrm{SC}+($ IoT or Internet of Things);

5. SC + (E-Governance or e-government or Digital Governance or cybergovernment or cyber government or cyber-government);

6. SC + Democracy;

7. SC + (Social Participation or Social Science)

8. $\mathrm{SC}+(\mathrm{ICT}$ or Information and Communication Technologies).

9. $\mathrm{SC}+$ Blockchain.

Table 1 presents a summary of the results obtained from searchers on the number of publications for each of the aforementioned keywords, with data from 2016 to 2019. The search was limited to a query on: Keywords, title and abstract. Topics related to operations research and SC were mostly found on IEEEXplore; perhaps this is because they are a more technically focused publisher. As it can be noticed, blockchain is a notorious emerging topic, with less than 100 publications per publisher until 2018.

Table 1. Keywords searched in three different reference databases.

\begin{tabular}{|c|c|c|c|c|c|c|c|c|c|}
\hline & \multicolumn{9}{|c|}{ Keywords } \\
\hline & [1] & [2] & [3] & [4] & [5] & [6] & [7] & [8] & [9] \\
\hline & \multicolumn{9}{|c|}{2016} \\
\hline Web of Science & 2073 & 44 & 289 & 436 & 41 & 6 & 55 & 213 & 2 \\
\hline SCOPUS & 2466 & 54 & 356 & 465 & 20 & 11 & 92 & 201 & 3 \\
\hline \multirow[t]{2}{*}{ IEEEXplore } & 1772 & 1178 & 153 & 399 & 19 & 2 & 101 & 381 & 3 \\
\hline & \multicolumn{9}{|c|}{2017} \\
\hline Web of Science & 2913 & 60 & 389 & 721 & 57 & 16 & 65 & 302 & 10 \\
\hline SCOPUS & 4750 & 100 & 472 & 829 & 31 & 15 & 132 & 292 & 22 \\
\hline \multirow[t]{2}{*}{ IEEEXplore } & 2038 & 1199 & 533 & 688 & 17 & 11 & 111 & 487 & 10 \\
\hline & \multicolumn{9}{|c|}{2018} \\
\hline Web of Science & 3034 & 66 & 361 & 920 & 69 & 14 & 65 & 312 & 47 \\
\hline SCOPUS & 6092 & 124 & 568 & 1454 & 46 & 13 & 145 & 396 & 99 \\
\hline \multirow[t]{2}{*}{ IEEEXplore } & 3227 & 2259 & 191 & 1051 & 27 & 4 & 142 & 519 & 89 \\
\hline & \multicolumn{9}{|c|}{2019} \\
\hline Web of Science & 2603 & 44 & 325 & 767 & 75 & 14 & 71 & 262 & 66 \\
\hline SCOPUS & 6418 & 121 & 604 & 1524 & 31 & 18 & 121 & 465 & 189 \\
\hline IEEEXplore & 2333 & 1547 & 157 & 917 & 24 & 4 & 127 & 532 & 110 \\
\hline
\end{tabular}

Figure 3a, created with data from SCOPUS database [41], represents the evolution of publications in the theme "smart city", with absolute values by year; the total number is 20,513 by published documents. The starting year of this search was chosen from the time when the first idea that refers to SC appeared, around 1997. The first values represent the sum from 1997 to 2006, since the number of published documents is minimal. Any findings, including the term in the title, abstract or keywords (both the singular and plural), were considered. Figure $3 \mathrm{~b}$ contains a pie chart showing the percentage of published documents by subject area, with a total sum of 52,336 publications (some documents fall within more than one subject area). It is possible to verify that computer science $(16,500)$ and engineering $(9877)$ comprise the largest portion of publications in SC topics from 1997 to 2019. In this chart, "others" represents the following areas: Chemistry (686); medicine (387); arts and humanities (360); biochemistry, genetics and molecular biology (344); chemical engineering (186); agricultural and biological sciences (149); psychology (122); health professions (90); multidisciplinary 
(67); pharmacology, toxicology and pharmaceutics (59); neuroscience (28); nursing (15); veterinary (9); immunology and microbiology (8); dentistry (3); and undefined (3).

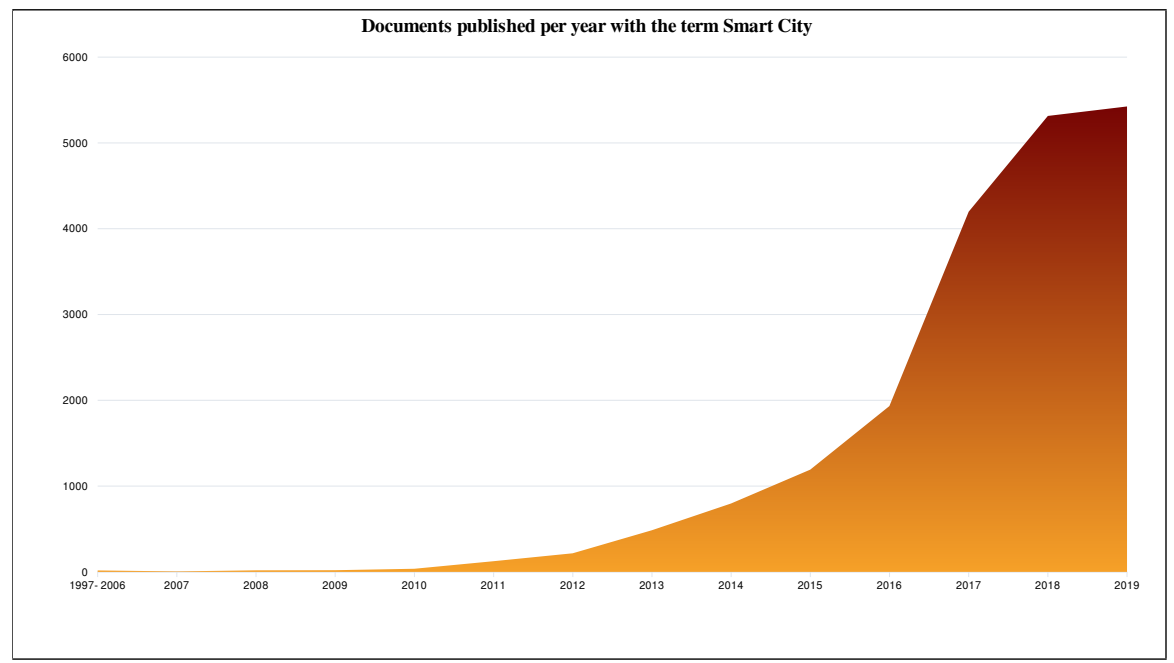

(a) Evolution of the term "smart city" in published papers, from 1997 to 2019, in the SCOPUS database.

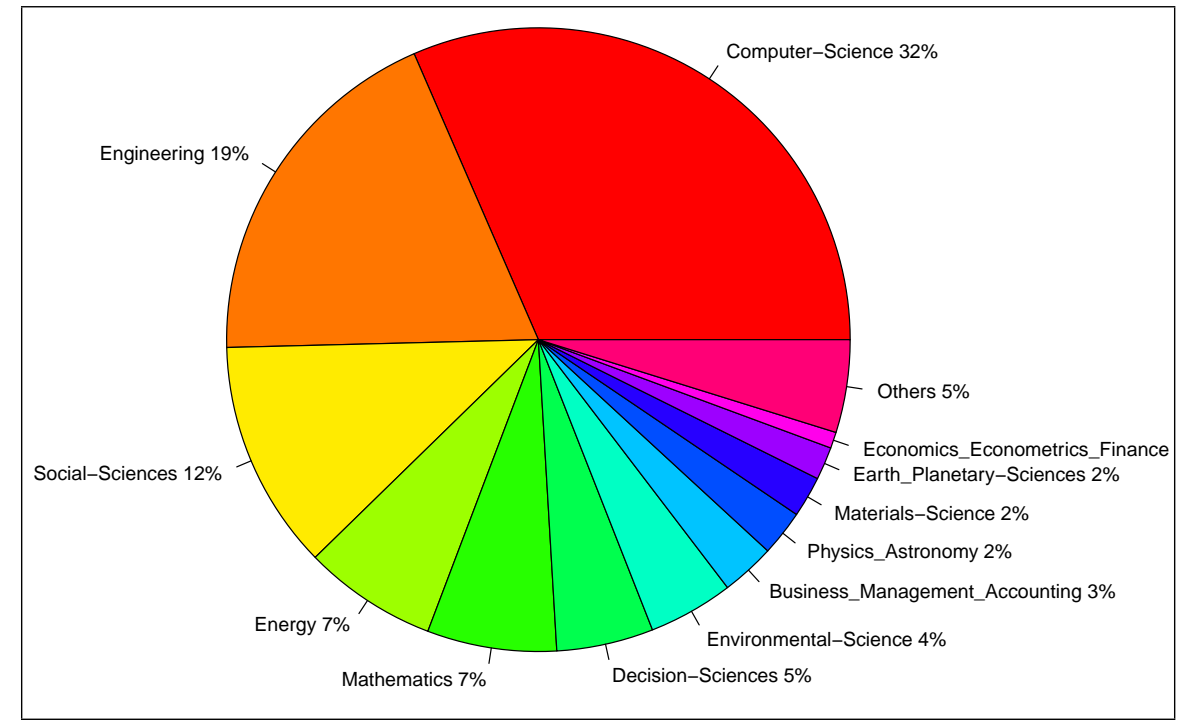

(b) "smart city" by published areas.

Figure 3. Data obtained from SCOPUS database with the term "smart city" from 1997 to 2019.

Social science represents the third biggest portion among the published document (according to the data provided in Figure 3b); in this sense, we highlight the importance of connecting SC with other areas. Citizens and local government [43] represent an important relationship to be highlighted and reinforced. Thus, to think of a city adapted to the citizen, in a way to facilitate other services beyond mobility, is necessary. In this context, it is extremely important to brainstorm models about how the citizens can effectively participate in cities' decisions in a democratic and simple way. Section 3.4 presents e-governance, a paradigm with potential for guiding these aforementioned steps.

\section{ICT and Emerging Technologies for Cities and Citizens}

Emerging technologies and SC models/paradigm are bringing a new wave of decentralized approaches, both in terms of resource allocation, governance models and opportunities for innovation. Section 3.1 introduces blockchain and its use in the context of smart cities. Section 3.2 presents some 
challenges for promoting more interactive infrastructure. Section 3.3 promotes the use of technologies that facilitate tourism and encourage visitors to explore a city. Section 3.4 introduces concepts of decentralized governance in the context of digital cities and the possibilities that systems such as blockchain are creating. Section 3.5 discusses how privacy may affect citizens' experience and points out benefits in embedding privacy in products and services. Section 3.6 shows how the motto of smart cities can boost innovation and provide possibilities for novel initiatives.

\subsection{Blockchain and Smart Cities}

Blockchain based technologies, also known as "distributed ledgers" techniques [44-47], encompass a family of applications that focus on enhancing trust between parties. They have been gaining attention since the appearance of Bitcoin cryptocurrency [19] and also have the potential to reduce costs [48,49].

While many private applications are already running on blockchain, public use of its concepts is just starting to appear, focusing on different aspects of the relationship between entities of the government, citizens, entrepreneurs and industries. For example, in Brazil, the BNDES (National Bank of Development) has been designing a smart contract for management of public funds when bidding happens [50]. Another use case in Brazil involves medical records with transparency, privacy, agility and low cost. Moreover, its use for emission, tracking and verification of official certificates/diplomas has been the focus of some Brazilian entities and also Spanish initiatives [51].

Blockchain can intrinsically promote transparency [52] when correctly used. The first applications were basically on the financial sector and, nowadays, are covering other vertical markets that want to integrate it for different asset management. In the context of SC, few applications can still be found. The work of Aggarwal et al. (2019) [53] introduces the use of blockchain in decentralized architecture between different geo-located IoT nodes in an "increasingly digitalized society (e.g., smart city)". The authors mentioned an increasingly digitalized society as also a core of a smart city, connecting it with the need of blockchain for managing key components of a distributed IoT network of devices. Naturally, some applications dealt with privacy concerns [54], since blockchain provides, for the first time in history, an open-source public infrastructure of cryptographic functions that enables applications related to privacy, such as the peer-reviewer process of scientific papers. Other applications are going beyond, such as Patel and Patel (2020) [55], which emphasizes that the technology of Distributed Applications (DApps) can handle the cities' data storage, data management, smart contracting, authentication, validation and trust-free transaction handling, and enable a shared economy. As highlighted by them, in the era of smart cities, it is inevitable to not consider a technology that provides immutable and transparent communication between interested parties. The work of Hakak et al. (2020) [56] mentioned that the purpose of SCs is also to enhance the quality of life for citizens dwelling within them. They made an effort in identifying blockchain components for working along with IoT and cloud computing. Some works of the literature considered blockchain for reputation [57] and payments on intelligent transportation systems [58], which is a topic of great interest for citizens, since many users are already registered with Uber and other private companies, which do not provide such decentralization of their services. The need of blockchain for these kind of services is essential for avoiding censorship and unfair behavior of companies.

While many works in the literature mentioned blockchain for IoT applications, we emphasize here that it also promotes, for the first time in history, IoV, which can be a path for monetization of different services provided by cities, as well as a channel for rewarding citizens. In the next subsections, blockchain concepts will be used in order to exemplify tools that blockchain can enable, as well as to work in parallel with existing solutions.

\subsection{Challenges on Infrastructure}

The wave of innovation in smart cities brings new interactive layers to cities, while it also simplifies and removes barriers from previous models. The key pillars are located in the interconnected sensors, 
intelligent transportation systems (metro, train, drones), public space with gardens, automatic and efficient lighting, gas system, water, telecommunication and infrastructure for energy sharing.

Sensors and smart devices can be used to solve problems of urban traffic, optimizing current transportation systems and assisting the design of emerging ones [59]. Microgrid houses are generating electricity, known as prosumer (producer + consumer); these decentralized generation systems $[60,61]$ also bring solutions to some areas of a city and also promote interaction of citizens and the possibilities that energy brings. Besides promoting sustainability, with the advance of cryptocurrencies, energy can also be a path to monetization, as introduced in Section 3.1.

Well-designed urban planning, associated with multi-criteria analysis about citizens' goals and wishes related to cities' services can guide a more sustainable transition. Studies of SC $[62,63]$ can boost more effective mobility and fairer access to opportunities, especially for urban populations. Logistics involve citizens' life quality in different aspects, such as air quality, noise, access time to cities key point and security, among others.

These topics are naturally complex because they involve the sense of each individual; what could be an optimal solution for one is not the same for another. For this purpose, online software can play a vital role in assisting each specific person to follow their goal within a city. In this sense, vehicle routing problems [64] should consider these "green" variables, promoting sustainable routing that ponders citizens' desires, both for daily locomotion but also for medium-term projections about the most suitable place to live.

Cisco and New York City introduced a project named City 24/7, which seeks to provide information from open government programs, local business and citizens to provide meaningful and powerful knowledge anytime, anywhere, on any device. These interactive screens include touch screen, voice and audio technology and provide real-time offers. Besides that, these platforms can be accessed by low range communication protocols using smartphones [65], tablets and portable computers. Being located at bus stops, train stations, major entryways, shopping mall and other places, this platform informs, protects and revitalizes. Those types of screens are used for facilitating and instructing citizens regarding distinct services within cities, such as informing the population about the next buses on the way, as well its position in the route and expected times. The location of the bus is available for any smartphone that connects in the network or knows a pre-defined code available at bus stations on the screens. In particular, the work of Oliveira et al. (2020) [58] drafted a smart contract that could manage a transportation service with a payment system working with crypto tokens and optional data protection.

In order to determine "optimal" areas for installing such interactive screens, it is necessary to consider the set of streets, flow of citizens along the roads, position of the screen on the street and the costs, among other things. Operation research techniques can help decision making and minimization of involved costs. Besides that, determining a set of relevant information, considering the profile of each individual that accesses the device, is another possible problem to be dealt with. In this case, the system could consider individuals' preferences and the current wishes of those accessing the platform. This direct marketing problem [66] should present suitable offers for each person, promoting the local communities [67], increasing cities' income and social welfare and urban cleaning, among other things.

Multi-modal transportation is an interesting decision making process, as emphasized in [68] and [69], which highlighted optimization mechanisms and multi-criteria decision making for finding best sets of routes according to the different needs of each individual. As an example, Figure 4 depicts an illustrative example of the routes provided by Google Maps in Osaka, Japan. As can be verified, even the most suitable wagon of the metro is indicated in the app. 


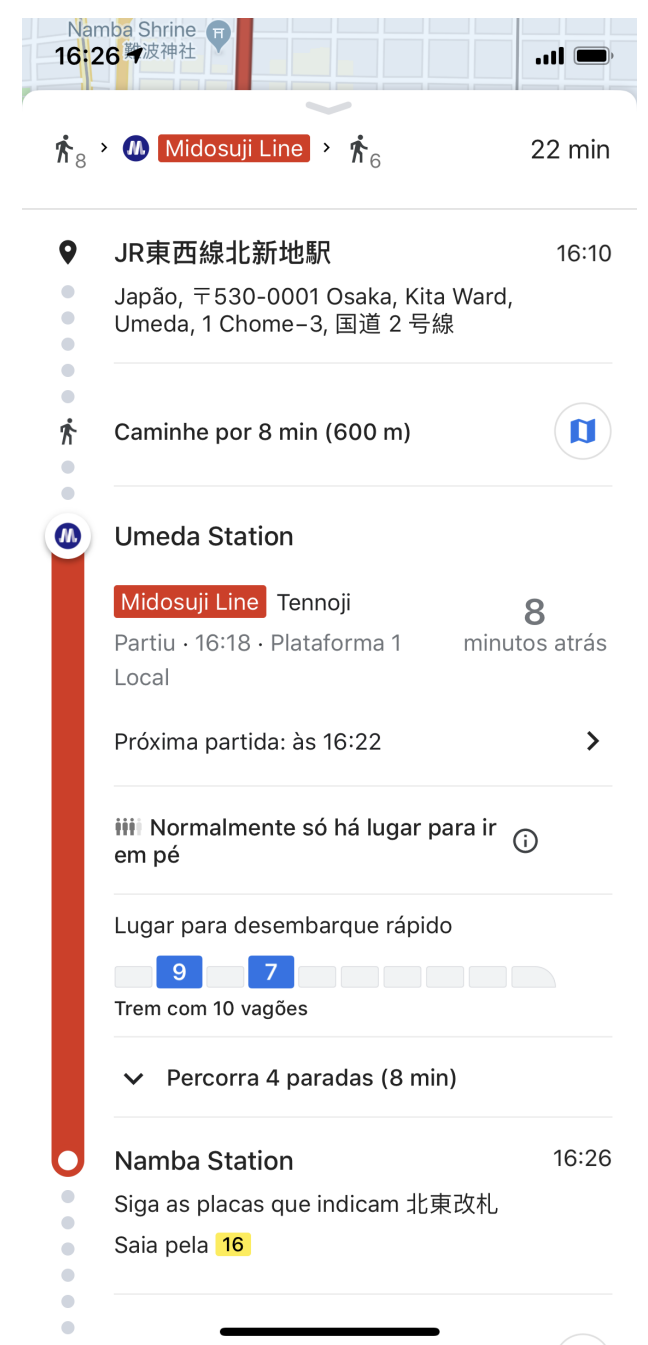

Figure 4. Google Maps routes showing faster wagons for landing, Osaka/Japan.

\subsection{Improving Visitors' Experience}

Protection of cultural heritage cities [70] is also within the scope of digital cities. SCs' interactive museums [71] are being inaugurated; they can guide the flow of information, such as news and technologies. For example, the Center for Teaching and Research in the Social Sciences and Contemporary History of Brazil from Getulio Vargas Foundation was founded in 1973, motivated by a need of conservation policies and digital dissemination [72]. The center contains the largest collection of personal archives from Brazilians' public figures, oral histories and audiovisual, covering social area, health care and architecture, among other things [73]. In this era of online available documents, this center verified the necessity of preserving its documents; in this sense, since 2010 they have been digitizing their collection (according to specific calls and actions), using semantic technologies, ICT, open linked data concepts and signal processing techniques. Since access is open in their domain, the collection has been considered to be relevant for both national and international studies. Sun et al. (2016) [27] comment that SC has a challenge to develop technologies to protect heritage items [74].

Besides the material heritage there is the immaterial, which covers typical cultures of each region (such as folklore, dance and ritual, among others), which are difficult to monitor in depth. Such a fact also applies in the north part of Brazil, in the interior of Amazonas state, as well as in others areas of South America. Smart measures should promote access to technology in order to assist the indigenous 
people's immaterial heritage [75]. One option can be the introduction of novel tools for the indigenous to document their beliefs, promoting this material in a decentralized manner [76], through the Internet.

Computational intelligence based technologies such as interactive maps were discussed by Roche (2016) [77]. Visitors of a city [78] could get tokens when they visit strategic points marked on those interactive maps. The verification method and rewards could even be automatically managed by smart contracts, and the rewarding tokens could be minted by city authorities, representing a specific asset given by that community. Such tokens could be exchanged for services that benefit local communities and the city. The efforts that are being done for promoting green logistics of electric vehicles used in touristic routes [79] are also noteworthy and related to sustainability, and are connected with technologies such as blockchain [21]. Guiding each citizen to the area that they would like visit is a task that can provide different social and technical benefits. Towsend and Oakley (2014) [80] comment that future cities need to guide the citizens with on-time journeys. It is possible to emphasize that the technology comes to make the city and tourist relationship easier and more flexible, bringing proximity and integration. In this sense, visitors can be more involved in decisions, being informed about current government strategies, news and perspectives.

\subsection{Decentralized Governance}

As should be noticed, social science is becoming increasingly part of the smart city debate. Understanding citizens' views about where they live and how they feel is primordial. Assessments of some uses of ICT solutions have already revealed problems that can only be resolved by engaging citizens in planning processes. The concept of e-governance (also known as civic tech) has a role to play in how to engage citizens [81]. Summed up with this, we currently have a new wave of decentralization, which is crucial for low-cost and trusted governance. Concepts of blockchain should be carefully considered when e-governance is taken into account. For example, governance models such as the Neo Blockchain [82] are an example of successful association of digital assets and democracy. In this section, we emphasize some of these concepts related with a historical background of decentralization and e-governance.

Decentralized governance paradigms are now being frequently discussed [3], in particular, due to the recent advances in IoT and blockchain based solution which are turning the IoV [20] into a real tool for policy enforcement [83]. In this sense, there have been efforts in bringing more proximity between government and citizens [84-86]. Connected by a new era of information technologies, the SC drives a strong trend for decentralizing democracies [87], as mentioned by Roberts (2004) [88]. Decentralizing the decision-making process implies distributing decisions, a strategy that has been mainly adopted using the paradigm of Multi-Agent Systems (MAS) [89,90] concepts. The paradigm of MAS is related to devices achieving consensus [91] throughout negotiation protocols.

Democratic participation opens cognitive control of the state by the citizens through information technology applied for public transparency, such as using smart contracts [92]. Besides that, the concept of e-governance embraces strategic governance in management and institutional integration. Fundamental e-governance is based on an efficient governance of spaces and public services. Through this, the population can be more participatory and active during decision-making, both on small or medium scales, from neighborhoods to cities [93] and even on a wider global scale $[94,95]$.

However, it is visible that tools are still missing for these kind of decisions. One simple example can be seen inside residential condominiums [96], where an useful tool for decision-making does not exist and condominiums' meetings persist in happening in a huge portion of these organizations. A useful way to fix this problem would be the installation of novel devices (like tablets) to enable real-time decision-making. This example circles around private city concepts $[97,98]$.

The Internet has been adopted as the core for promoting more accessibility, a transformation that happens in a similar way as occurred with previous communications systems, from the telegraph to the TV. However, the Internet is allowing new forms of policy organization and, in society, increasing the 
capacity of impacts in some individuals previously not interested [99]. In addition, nowadays, through IoT, communication channels are being opened by a larger portion of our used-daily devices. The IoT and related technologies can be used for policy and democratic purposes by a series of social agencies: Citizens, government organizations, civil society organizations and political parties, among others. What is expected, in terms of democratic innovation, is a shared decision-making process that means expanding the civil autonomy and public relations [100]. This provides space for e-government [101], and even possibilities of Internet voting [102,103], legislative and juridical decision-making $[87,104]$ and public petitioning.

Dispute resolution based on blockchain solutions has also been developed, in a system called Kleros [105]. These processes are called civic tech, teledemocracy, digital democracy, electronic democracy, digital government, open administration, cyberdemocracy [100] or e-democracy [106]. Online forums, focused, for example, on allowing discussions on specific issues, are a consolidated way for providing an open environment for political activists and the opinions of sympathizers [107]. The blockchain guarantees forums of information permanently saved in an "immutable form"; in a way there are no changes or alterations [108] given that certificates are permanently stored. The immutability should be seen as a decentralized decision-making process, in which involved stakeholders can decide on the path they want to follow. In the case of the Ethereum and Bitcoin projects, one block finality is not achieved; in this sense, the chain can suffer deep reorganization (more details at https:/ / en.bitcoin.it/wiki/Chain_Reorganization) if the majority of the nodes agree with the longest chain. Furthermore, the case in which Ethereum suffered an attack (on the occurrence of news about the DAO vulnerability: https:/ /blog.ethereum.org/2016/06/17/ critical-update-redao-vulnerability/) can be seen as an example of how discussions can reach a consensus of rolling the chain back to a point in which the state machine [109] was not affected. On the other hand, other protocols have block finality, such the Neo Blockchain [44], in which an MAS based consensus (namely, delegated byzantine fault tolerance) is held and nodes can not generate blocks in another branch, generating no forks. However, it is noteworthy that public blockchains have this nature of decentralization. Thus, in this sense, even in the case of the roll back of Ethereum, the chain that had been attacked still exists (namely, Ethereum Classic). Thus, the immutability in fact happens, but can be forgotten if the majority agrees to not consider that branch. The blockchain promotes the warranty of original information without changes. It is possible to conclude that the Internet is positively used in this context, helping in decision-making, improving communication models and data storage.

\subsection{Citizens' Privacy}

An increase in security usually implies less privacy. For example, with cameras to control the security and citizens' traffic, the citizens' identity and data become more visible [110,111], which is another reason why cryptography and blockchain become even more important topics. In 2019, some states of the USA banned the use of individual images in different situations, such as facial recognition; a requirement that fits the context of digital IDs and access to private data provided by blockchain. Applications for such public transparency need to be carefully addressed philosophically, as discussed by Byung-Chul Han, since trust should be kept as a main value between partnerships during exchange of information and assets. Recently, the philosopher has made some notes regarding the recent events related to the coronavirus outbreak [112,113]. He emphasizes that Asian countries have been using support of digital surveillance to fight the virus, while Western countries have been struggling with data regulations. He points out that it is possible that in the future the state will also have digital access to body temperature, weight and blood sugar level, among other things. In his insight, he highlights ICT tools such as notifying citizens that a given place has someone infected such as the Korean Corona App, a publicly available application that can inform citizens of known cases considering their current position [114]. However, concerns regarding the use of such data by Western states were also asserted by him. 
CISCO [115] pointed out that investments on privacy have a positive return on investment. An appealing to blockchain is related to its features of transparency instead of the taboo of promoting anonymity [54]. Blockchain [116] plays a fundamental role in information access, mainly by using smart contracts [117] to ensure transparent protocols. IoV brings this optional potential of transparency by promoting a trusted network of computers which can work following different consensus mechanisms such as proof-of-work, proof-of-stake and other voting/negotiation systems. Examples of real-world use of asset exchanges can be seen in Bitcoin, Dash, Monero, ZCash and other emerging cryptocurrencies. Some of them have embedded anonymity and optional possibility of transparency. While enabling optional trust you preserve individual privacy [118] and enable an auditable system for special cases in which it may be needed. Yeh (2017) [2] mentioned that citizens show up to be excited if the ICT technologies, to be embedded inside cities' services, have data privacy policies. In order to achieve another level of social participation, it is important to promote easier ways of accessing information.

In this context, discussions surrounding digital identities are attracting attention of different blockchain projects. For instance, Neo Blockchain currently has three different proposals for managing digital identities on a public blockchain [119-121], introduced at the end of 2019 and under discussion regarding implementation until the end of 2020.

\subsection{Innovation and Entrepreneurship in Smart Cities}

The label "smart" has become a motto; nowadays, there are: Smart waters, smart cars and smart washlets, among others. "Smart" is becoming a brand, which mostly involves devices, tools and software that facilitate daily life. Policies related to SC have been attracting attention from a police maker and the industry, raising funding over the last few years [122]. Studies from the literature have been exploring the role of cities in enabling and facilitating digital entrepreneurship [123].

There is an open space for innovation when we take into account the sea of services that need minor adjustments. One of the bold ambitions is related to increasing the competitiveness of local communities [124], which has been one of the aims of scholars, practitioners and policy makers interested in this phenomenon. By promoting sustainable territorial development [13] there is a path for a sustainable transformation which would encompasses regulations but still boost innovation on the local scale. A case of study in Finland [125] notes that microenterprises need help with exploiting digitalization, indicating the potential that initiatives such as those commented on in this study can assist in that task.

Another interesting trend is in connection with the digitization of assets [126], which is promoting marketplaces for real-time exchange of value, not only involving cryptocurrencies such as bitcoin. This new trend is allowing citizens to interact with a variety of services by means of digital tokens that serve as utility such as the well-known mileage programs.

Lindgren et al. (2019) [127] comment on the digitalizations of public services that reduce the integration and duration of the citizen-governance interaction, but also require skills by providers and the population to use digital tools. Aligned with what was presented at Section 3.5, digital identities play another role in facilitating entrepreneurship, cutting the red tape of several processes as well as reducing costs.

\section{Final Considerations}

\subsection{Conclusions}

This study highlighted the evolution of concepts surrounding cities, an intrinsic part of modern society. Assisted by an analyses of the smart cities concepts and potential trends, this paper contributes with an updated position of cities' challenges, suggesting innovative opportunities, as can be seen in summary in Table 2. 
Table 2. Summary of observations from key sub-categories with authors' analysis.

\begin{tabular}{ll}
\hline Sub-Categories & Descriptions/Observations \\
\hline & \\
It has been observed that works \\
from the literature mention \\
that smart cities' pillars are \\
infrastructures throughout sensors \\
and digital equipment; \\
These tools enable real time \\
information sharing such as \\
schedules of public transport, \\
police and fire service stations, \\
events, parks and outdoors \\
activities, as well as a transparent \\
layer for the use of technologies.
\end{tabular}

Authors' Recommendations

- $\quad$ ICT enables a new layer for a direct flow of information with citizens and services (an interactive layer);

- $\quad$ One of the expected goals of ICT services is to provide relevant information for citizens, but few applications are really focused on User Experience (UX);

- We have the challenge of promoting the digitalization of cities' services, thinking of users' perspectives;

- This digitalization is not only a goal of the public administration but also of the software industry interested in attracting users to their platforms.

- $\quad$ Technologies aligned with the scope of SC have been bringing tools and discussions to this topic;

- Policymakers need to understand that

- $\quad$ Citizens can contribute to society

Governance through voting and other forms of social participation. modern forms of governance need to rely on digital technology;

- $\quad$ For achieving that, new frameworks need to be developed, providing easy access, facility, trust and transparency;

- Decentralized technology is a key concept for governance and is just starting to be explored and investigated.

- Few applications and connections with cities and citizens are currently available in the literature, which is a challenge to be faced by researchers;

- This tech and its application are becoming reality in some countries, with ideas that are starting to be implemented, but are not fully functional yet;

Blockchain

- It is recognized that this technology can support city initiatives for facilitating data transparency and trustless applications.
- We have distinct limitations when using public chains. Thus, private chain interaction with public chains can provide a framework for different applications that preserve citizens' privacy and provide them a path for monetization.

It was highlighted that applications focused on citizens may promote decision making in a more effective way, both in urban centers and in small communities. As emphasized, digital technologies possess an important role to coordinate and optimize decisions, mainly due to the transformations regarding novel forms of governance.

\subsection{Research Implications}

The paper instigates a look on citizen relationships in a way to promote awareness among citizens regarding technological and digital evolution. Academicians can benefit from its insights in order to 
find open problems and fields for improving a city, while the industry and cities' decision makers can use this study for guiding medium-long term plans for a sustainable transition.

In order to reduce the gap between citizens and technologies there is a need for more interactive systems, both on key points of a city and also better interfaces provided by the industry and the government. By facilitating access to governance tools, citizens will have quick access to services that assist their participation, wherever they are. For achieving that, society needs to rely on state-of-the-art technologies such as blockchain, which can act as a fundamental tool for trust, transparency and efficiency, supported by the evolution of equipment that ICT promotes. There is still a challenge in connecting social sciences with technologies; a huge portion of society still doubts that the technological evolution can improve life quality. It is a challenge to create awareness that the point we already reached in society was due to scientific advances and, at the end of the day, we still need our focus and efforts on that. While works from the literature have not yet directly focused on that, this study has the potential to create awareness of the academy and also boost startups to invest in emerging technologies and the development of highly interactive platforms. It is necessary to motivate investments and policies on topics related to citizens' participation in government decisions. These measures can provide opportunities for innovation connected with the use of those emerging tools.

Besides that, it is possible that a paradigm change, in the form of urban planning, will also be relevant. During this next decade, ICT and decentralized technologies, such as blockchain, are going to have an important role in processing data, communicating with citizens and assisting decision making through optimization tools, boosting the advance of social concepts surrounding governance and smart cities.

For instance, we conclude this paper by exemplifying a case in which some of the concepts of this research could be applied for a sustainable supply chain. Every worker would have his or her digital identity registered on a blockchain, as well as his or her historically relevant data such as vaccines and risks over the last days/weeks. Each farm and production line step of the supply chain would be registered in a distributed ledger through a smart contract. The way in which the soil and plants are treated could also be recorded on the blockchain in order to convey transparency for the production. This procedure facilitates certificates to be emitted (such as those for organic food). Following this line of reasoning, each truck used for collecting grains of coffee would be registered and those unloading them on the industry could take the necessary measures and keep the supply chain up to date. The final coffee obtained by a client could be scanned with a quick response code (or radio-frequency identification) that would provide awareness of the path the product has taken until its destination. Finally, clients could also provide scores and opinions on that product, affecting economical incentives provided for supporting that production.

This exemplifies a scenario in which citizens are provided with tools for tracking information that they desire to search for, as well as topics they want to give their opinions on.

Author Contributions: T.A.O. conducted this study as part of her PhD, advised by H.R. and M.O. All authors have read and agreed to the published version of the manuscript.

Funding: Thays A. Oliveira would like to thank the partnership with NeoResearch Community and support of Neo Foundation. Miquel Oliver was supported by the Spanish Government under projects TEC2016-79510-P (Proyectos Excelencia 2016); Miquel Oliver and Helena Ramalhinho were also supported by the 2017-SGR-1739 grant.

Acknowledgments: Thays A. Olivera would like to thanks the Creating.City team (https:/ / creating.city/) for the organization of several workshops, conferences, round tables and the editorial process of a book published on Springer [128], which were important for motivating the writing of this article. In particular, Vitor N. Coelho and Igor M. Coelho for their valuable contributions and revisions. Finally, Maria Emília Junqueira for her professional English editing and revising over this paper.

Conflicts of Interest: The authors declare no conflict of interest. 


\section{Abbreviations}

The following abbreviations are used in this manuscript:

$\begin{array}{ll}\text { DApps } & \text { Distributed Applications } \\ \text { E-governance } & \text { Electronic governance } \\ \text { ICT } & \text { Information and Communication Technology } \\ \text { IoT } & \text { Internet of Things } \\ \text { IoV } & \text { Internet of Value } \\ \text { MAS } & \text { Multi-Agent Systems } \\ \text { SC } & \text { Smart City } \\ \text { UX } & \text { User Experience }\end{array}$

\section{References}

1. Evans, A.M.; Campos, A. Open government initiatives: Challenges of citizen participation. J. Policy Anal. Manag. 2013, 32, 172-185. [CrossRef]

2. Yeh, H. The effects of successful ICT-based smart city services: From citizens' perspectives. Gov. Inf. Q. 2017, 34, 556-565. [CrossRef]

3. Coe, A.; Paquet, G.; Roy, J. E-governance and smart communities: A social learning challenge. Soc. Sci. Comput. Rev. 2001, 19, 80-93. [CrossRef]

4. Dameri, R.P.; Cocchia, A. Smart city and digital city: Twenty years of terminology evolution. In Proceedings of the X Conference of the Italian Chapter of AIS, ITAIS, Universitá Commerciale Luigi Bocconi in Milan, Italy, 14 December 2013; pp. 1-8. [CrossRef]

5. Gibson, D.V.; Kozmetsky, G.; Smilor, R.W. The Technopolis Phenomenon: Smart Cities, Fast Systems, Global Networks; Rowman \& Littlefield: Lanham, MD, USA, 1992.

6. Stephen, G.; Marvin, S. Telecommunications and the City: Electronic Spaces, Urban Places; Routledge: Abingdon, UK, 1996.

7. Graham, S. Telecommunications and the future of cities: Debunking the myths. Cities 1997, 14, 21-29. [CrossRef]

8. Anthopoulos, L. Smart utopia VS smart reality: Learning by experience from 10 smart city cases. Cities 2017, 63, 128-148. [CrossRef]

9. Bina, O.; Inch, A.; Pereira, L. Beyond techno-utopia and its discontents: On the role of utopianism and speculative fiction in shaping alternatives to the smart city imaginary. Futures 2020, 115, 102475. [CrossRef]

10. Afonso, R.A.; dos Santos Brito, K.; do Nascimento, C.H.; Garcia, V.C.; Álvaro, A. Brazilian smart cities: Using a maturity model to measure and compare inequality in cities. In Proceedings of the 16th Annual International Conference on Digital Government Research, Phoenix, AZ, USA, 27-30 May 2015; pp. 230-238. [CrossRef]

11. Albino, V.; Berardi, U.; Dangelico, R.M. Smart cities: Definitions, dimensions, performance, and initiatives. J. Urban Technol. 2015, 22, 3-21. [CrossRef]

12. Ahvenniemi, H.; Huovila, A.; Pinto-Seppä, I.; Airaksinen, M. What are the differences between sustainable and smart cities? Cities 2017, 60, 234-245. [CrossRef]

13. Barbosa, A.C.; Moraes, T.M.; Tesima, D.T.; Pontes, R.C.; de Sá Motta Lima, A.; Azevedo, B.Z. Smart Planning: Tools, Concepts, and Approaches for a Sustainable Digital Transformation. In Smart and Digital Cities: From Computational Intelligence to Applied Social Sciences; Springer: Cham, Switzerland, 2019; pp. 221-236. [CrossRef]

14. Sadin, É. L'humanité augmentée. L'administration Numérique du Monde; Échappée (L'): Paris, France, 2013; ISBN 978-2915830750.

15. Han, B.C. Transparenzgesellschaft; Matthes \& Seitz Berlin Verlag: Berlin, Germany, 2015.

16. Gilman, H.R. Civic Tech For Urban Collaborative Governance. PS Political Sci. Politics 2017, 50, 744-750. [CrossRef]

17. Guimarães, J.C.F.D.; Severo, E.A.; Júnior, L.A.F.; Costa, W.P.L.B.D.; Salmoria, F.T. Governance and quality of life in smart cities: Towards sustainable development goals. J. Clean. Prod. 2020, 253, 119926. [CrossRef] 
18. Boehner, K.; DiSalvo, C. Data, design and civics: An exploratory study of civic tech. In Proceedings of the 2016 CHI Conference on Human Factors in Computing Systems, San Jose, CA, USA, 7-12 May 2016; pp. 2970-2981. [CrossRef]

19. Nakamoto, S. Bitcoin: A Peer-to-Peer Electronic Cash System; White Paper; 2008. Available online: https: / / git.dhimmel.com/bitcoin-whitepaper/ (accessed on 13 September 2017).

20. Truong, N.B.; Um, T.W.; Zhou, B.; Lee, G.M. Strengthening the blockchain-based Internet of value with trust. In Proceedings of the 2018 IEEE International Conference on Communications (ICC), Kansas City, MO, USA, 20-24 May 2018; pp. 1-7. [CrossRef]

21. Sun, M.; Zhang, J. Research on the application of block chain big data platform in the construction of new smart city for low carbon emission and green environment. Comput. Commun. 2020, 149, 332-342. [CrossRef]

22. Lévy-Bencheton, C.; Darra, E.; European Union Agency for Network and Information Security. In Cyber Security for Smart Cities: An Architecture Model for Public Transport; ENISA: Heraklion, Greece, 2015; ISBN 978-92-9204-162-5. [CrossRef]

23. Oliveira, T.A.; Coelho, V.N.; Tavares, W.; Ramalhinho, H.; Oliver, M. Operational and digital challenges to connect citizens in smart cities (In portuguese). In Proceedings of the XLIX Annual Brazilian Symposium on Operational Research, Blumenau, Brazil, 17-30 August 2017; pp. 3819-3830.

24. Creating City. Proceedings organized by the Creating. City Team. 2020. Available online: https://creating. city/ (accessed on 3 February 2020)

25. Yin, C.; Xiong, Z.; Chen, H.; Wang, J.; Cooper, D.; David, B. A literature survey on smart cities. Sci. China Inf. Sci. 2015, 58, 1-18. [CrossRef]

26. Sassen, S. The global city: Introducing a concept. Brown J. World Aff. 2004, 11, 27.

27. Sun, Y.; Song, H.; Jara, A.J.; Bie, R. Internet of Things and Big Data Analytics for Smart and Connected Communities. IEEE Access 2016, 4, 766-773. [CrossRef]

28. Yao, T.; Huang, Z.; Zhao, W. Are smart cities more ecologically efficient? Evidence from China. Sustain. Cities Soc. 2020, 102008. [CrossRef]

29. International Standards Organization. Smart Cities-Preliminary Report 2014; ISO 2015: Geneva, Switzerland, 2014.

30. Bollier, D. How Smart Growth Can Stop Sprawl: A Fledgling Citizen Movement Expands; Essential Books; Essential Books: Washington, DC, USA, 1998.

31. Hou, Q.; Li, W.; Zhang, X.; Fang, Y.; Duan, Y.; Zhang, L.; Liu, W. Intelligent urban planning on smart city blocks based on bicycle travel data sensing. Comput. Commun. 2020, 153, 26-33. [CrossRef]

32. Lennard, S.H.C. Livable Cities: Concepts and Role in Improving Health. In Integrating Human Health into Urban and Transport Planning; Springer: Cham, Switzerland, 2019; pp. 51-71.

33. Zhuhadar, L.; Thrasher, E.; Marklin, S.; de Pablos, P.O. The next wave of innovation-Review of smart cities intelligent operation systems. Comput. Hum. Behav. 2017, 66, 273-281. [CrossRef]

34. Taylor, P.J.; Derudder, B. World City Network: A Global Urban Analysis; Routledge: Abingdon, UK, 2015. [CrossRef]

35. Zambonelli, F. Toward Sociotechnical Urban Superorganisms. Computer 2012, 45, 76-78. [CrossRef]

36. Paulin, A.A. Informating public governance: Towards a basis for a digital ecosystem. In Open Government: Concepts, Methodologies, Tools, and Applications; IGI Global: Hershey, PA, USA, 2020; pp. 1534-1555. [CrossRef]

37. Evans, M.; Dunleavy, P.; McGregor, C.; Halupka, M. 10 Towards digital era governance: Lessons from the Australian experience. In A Research Agenda for Public Administration; Elgar Research Pub: Cheltenham, UK, 2019; p. 146. [CrossRef]

38. Chamoso, P.; González-Briones, A.; Prieta, F.D.L.; Venyagamoorthy, G.K.; Corchado, J.M. Smart city as a distributed platform: Toward a system for citizen-oriented management. Comput. Commun. 2020, 152, 323-332. [CrossRef]

39. Batty, M. Big data, smart cities and city planning. Dialogues Hum. Geogr. 2013, 3, 274-279. [CrossRef]

40. Web of Science. Web of Science-Search for Smart Cities Publications; 2017. Available online: https://mjl. clarivate.com/home (accessed on 11 February 2020).

41. SCOPUS. Analyse Search Results-Search for Smart Cities Publications. 2017. Available online: https: / / www-scopus-com.sare.upf.edu/search/form.uri?display=basic (accessed on 11 February 2020).

42. IEEEXplore. Analyse Search Results-Search for Smart Cities Publications. 2017. Available online: https:/ /ieeexplore.ieee.org/Xplore/home.jsp (accessed on 11 February 2020). 
43. Mossberger, K.; Wu, Y.; Crawford, J. Connecting citizens and local governments? Social media and interactivity in major US cities. Gov. Inf. Q. 2013, 30, 351-358. [CrossRef]

44. Da, F.; Zhang, E. NEO: A Distributed Network for the Smart Economy; Technical Report; NEO Foundation. Available online: https:/ / github.com/neo-project/neo (accessed on 28 March 2020).

45. Perlman, L. Distributed Ledger Technologies and Financial Inclusion; Technical Report; ITU-T Focus Group Digital Financial Services; 2017. Available online: https:/ /www.itu.int/en/ITU-T/focusgroups/dfs/Pages/ default.aspx (accessed on 20 March 2018).

46. Foundation, The Linux Introduction to Hyperledger Technologies. 2017. Available online: https: / / www. edx.org/course/blockchain-business-introduction-linuxfoundationx-lfs171x (accessed on 20 January 2018).

47. Blockchains for Social Good. Available online: https://ec.europa.eu/research/eic/index.cfm?pg=prizes_ blockchains (accessed on 10 December 2019).

48. Kshetri, N. Can blockchain strengthen the Internet of things? IT Prof. 2017, 19, 68-72. [CrossRef]

49. Sun, J.; Yan, J.; Zhang, K.Z. Blockchain-based sharing services: What blockchain technology can contribute to smart cities. Financ. Innov. 2016, 2, 26. [CrossRef]

50. BNDES. BNDES Token. 2020. Available online: https://github.com/bndes/bndestoken (accessed on 15 February 2020.)

51. Oliver, M.; Moreno, J.; Prieto, G.; Benítez, D. Using blockchain as a tool for tracking and verification of official degrees: Business model. In Proceedings of the 29th European Regional Conference of the International Telecommunications Society (ITS): “Towards a digital future: Turning technology into markets?”, Trento, Italy, 1-4 August 2018.

52. Dobrovnik, M.; Herold, D.; Fürst, E.; Kummer, S. Blockchain for and in Logistics: What to Adopt and Where to Start. Logistics 2018, 2, 18. [CrossRef]

53. Aggarwal, S.; Chaudhary, R.; Aujla, G.S.; Kumar, N.; Choo, K.K.R.; Zomaya, A.Y. Blockchain for smart communities: Applications, challenges and opportunities. J. Netw. Comput. Appl. 2019, 144, 13-48. [CrossRef]

54. Makhdoom, I.; Zhou, I.; Abolhasan, M.; Lipman, J.; Ni, W. PrivySharing: A blockchain-based framework for privacy-preserving and secure data sharing in smart cities. Comput. Secur. 2020, 88, 101653. [CrossRef]

55. Patel, V.; Patel, C. Blockchain Technology: An Aid to the Governance of Smart Cities. Adv. Intell. Syst. Comput. 2020, 933, 373-382. [CrossRef]

56. Hakak, S.; Khan, W.; Gilkar, G.; Imran, M.; Guizani, N. Securing Smart Cities through Blockchain Technology: Architecture, Requirements, and Challenges. IEEE Netw. 2020, 34, 8-14. [CrossRef]

57. Hîrtan, L.A.; Dobre, C.; González-Vélez, H. Blockchain-based reputation for intelligent transportation systems. Sensors (Switzerland) 2020, 20, 791. [CrossRef]

58. Oliveira, T.A.; Gabrich, Y.B.; Ramalhinho, H.; Oliver, M.; Cohen, M.W.; Ochi, L.S.S.; Gueye, S.; Protti, F.; Pinto, A.A.A.; Ferreira, D.V.M.V.M.; et al. Mobility, Citizens, Innovation and Technology in Digital and Smart Cities. Future Internet 2020, 12, 22. [CrossRef]

59. Clarke, R.Y. Smart Cities and the Internet of Everything: The Foundation for Delivering Next-Generation Citizen Services; White Paper; Cisco: San Jose, CA, USA, 2013.

60. Coelho, V.N.; Coelho, I.M.; Coelho, B.N.; de Oliveira, G.C.; Barbosa, A.C.; Pereira, L.; de Freitas, A.; Santos, H.G.; Ochi, L.S.; Guimarães, F.G. A communitarian microgrid storage planning system inside the scope of a smart city. Appl. Energy 2017, 201,371-381. [CrossRef]

61. Darby, S.J. Chapter 2.6 - Energy, human activity, and knowledge: Addressing smart city challenges. In Energy and Behaviour; Lopes, M., Antunes, C.H., Janda, K.B., Eds.; Academic Press: Cambridge, MA, USA, 2020; pp. 237-260. [CrossRef]

62. Cano, J.; Hernández, R.; Ros, S. Distributed Framework for Electronic Democracy in Smart Cities. Computer 2014, 47, 65-71. [CrossRef]

63. Batty, M.; Axhausen, K.W.; Giannotti, F.; Pozdnoukhov, A.; Bazzani, A.; Wachowicz, M.; Ouzounis, G.; Portugali, Y. Smart cities of the future. Eur. Phys. J. Spec. Top. 2012, 214, 481-518. [CrossRef]

64. Coelho, V.; Grasas, A.; Ramalhinho, H.; Coelho, I.; Souza, M.; Cruz, R. An ILS-based algorithm to solve a large-scale real heterogeneous fleet VRP with multi-trips and docking constraints. Eur. J. Oper. Res. 2016, 250, 367-376. [CrossRef]

65. Falaki, H.; Govindan, R.; Estrin, D. Smart Screen Management on Mobile Phones; Center for Embedded Network Sensing: Los Angeles, CA, USA, 2009; pp. 1-10. 
66. Coelho, V.N.; Oliveira, T.A.; Coelho, I.M.; Coelho, B.N.; Fleming, P.J.; Guimarães, F.G.; Ramalhinho, H.; Souza, M.J.; Talbi, E.G.; Lust, T. Generic Pareto local search metaheuristic for optimization of targeted offers in a bi-objective direct marketing campaign. Comput. Oper. Res. 2017, 78, 578-587. [CrossRef]

67. Barbosa, A.C.; Oliveira, T.A.; Coelho, V.N. Cryptocurrencies for Smart Territories: An exploratory study. In Proceedings of the 2018 International Joint Conference on Neural Networks (IJCNN), Rio, Brazil, 8-13 July 2018; pp. 1-8. [CrossRef]

68. Silva, J.; Rampazzo, P.B.; Yamakami, A. Urban Mobility in Multi-Modal Networks Using Multi-Objective Algorithms. In Smart and Digital Cities: From Computational Intelligence to Applied Social Sciences; Springer: Cham, Switzerland, 2019; pp. 9-22. [CrossRef]

69. Shirabayashi, J.V.; Yamakami, A.; Silva, R.C.; Shirabayashi, W.V.I., Urban Transport and Traffic Systems: An Approach to the Shortest Path Problem and Network Flow Through Colored Graphs. In Smart and Digital Cities: From Computational Intelligence to Applied Social Sciences; Springer: Cham, Switzerland, 2019; pp. $23-43$. [CrossRef]

70. Lillevold, K.; Haarstad, H. The deep city: Cultural heritage as a resource for sustainable local transformation. Local Environ. 2019, 24, 329-341. [CrossRef]

71. Giannini, T. Museums and Digital Culture; Springer: Cham, Switzerland, 2019. [CrossRef]

72. Castro, R.M.D. Personal Files, Availability and Access on the Web: The case of CPDOC (In Portuguese). 2017. Available online: https:/ / cpdoc.fgv.br/ (accessed on 10 July 2019).

73. Rademaker, A.; Higuchi, S.; Oliveira, D.A.B. A Linked Open Data Architecture for Contemporary Historical Archives. In Proceedings of the 3rd International Workshop on Semantic Digital Archives (SDA 2013), Valetta, Malta, 26 September 2013; pp. 52-64.

74. Zhou, Y.; Sun, J.; Huang, Y. The Digital Preservation of Intangible Cultural Heritage in China: A Survey. Preserv. Digit. Technol. Cult. 2019, 48, 95-103. [CrossRef]

75. Hoffmann, Z. Information and communication technologies in bachelor degree of intercultural education of native ameridian teachers of Federal University of Goiás. Ph.D. Thesis, Postgraduate Program in Science and Mathematics Education. University of Goiás, Goiânia, Brazil, 2015.

76. Bueno, C. Comunidades indígenas usam Internet e redes sociais para divulgar sua cultura. Ciência E Cult. 2013, 65, 14-15. [CrossRef]

77. Roche, S. Geographic information science III Spatial thinking, interfaces and algorithmic urban places-Toward smart cities. Prog. Hum. Geogr. 2017, 41, 657-666. [CrossRef]

78. Matos, A.; Pinto, B.; Martins, S.; Martins, J.; Au-Yong-Oliveira, M. Smart Cities and Smart Tourism: What Future Do They Bring? In New Knowledge in Information Systems and Technologies; Rocha, Á., Adeli, H., Reis, L.P., Costanzo, S., Eds.; Springer: Cham, Switzerlands, 2019; pp. 358-370.

79. Karbowska-Chilinska, J.; Zabielski, P. Maximization of Attractiveness EV Tourist Routes. In Computer Information Systems and Industrial Management; Saeed, K., Homenda, W., Chaki, R., Eds.; Springer: Cham, Switzerlands, 2017; pp. 514-525. [CrossRef]

80. Townsend, P.S.; Oakley, C.F. Innovative provision for pedestrians in future intelligent cities. In Proceedings of the IET Conference on Future Intelligent Cities, London, UK, 4-5 December 2014; pp. 1-6. [CrossRef]

81. Gilman, H.R. Participatory Budgeting and Civic Tech: The Revival of Citizen Engagement; Georgetown University Press: Washington, DC, USA, 2016.

82. Elrom, E. NEO Blockchain and Smart Contracts. In The Blockchain Developer: A Practical Guide for Designing, Implementing, Publishing, Testing, and Securing Distributed Blockchain-based Projects; Apress: Berkeley, CA, USA, 2019; pp. 257-298. [CrossRef]

83. Neisse, R.; Steri, G.; Nai-Fovino, I. A blockchain-based approach for data accountability and provenance tracking. In Proceedings of the 12th International Conference on Availability, Reliability and Security, Reggio Calabria, Italy, 29 August-1 September 2017; p. 14. [CrossRef]

84. Almirall, E.; Wareham, J.; Ratti, C.; Conesa, P.; Bria, F.; Gaviria, A.; Edmondson, A. Smart Cities at the Crossroads: New Tensions in City Transformation. Calif. Manag. Rev. 2016, 59, 141-152. [CrossRef]

85. Odendaal, N. Towards the digital city in South Africa: Issues and constraints. J. Urban Technol. 2006, 13, $29-48$. [CrossRef]

86. Stepan, A. Brazil's Decentralized Federalism: Bringing Government Closer to the Citizens? Daedalus 2000, 129, 145-169. [CrossRef] 
87. Coelho, V.N.; Oliveira, T.A.; Figueiredo, I.V.O.; Souza, M.J.F.; Veloso, I. A Multicriteria View about Judicial and Legislative Decision Making in Digital Cities and Societies. In Smart and Digital Cities: From Computational Intelligence to Applied Social Sciences; Springer: Cham, Switzerlands, 2019; pp. 209-220. [CrossRef]

88. Roberts, N. Public Deliberation in an Age of Direct Citizen Participation. Am. Rev. Public Adm. 2004, 34, 315-353. [CrossRef]

89. Coelho, V.N.; Cohen, M.W.; Coelho, I.M.; Liu, N.; Guimarães, F.G. Multi-agent systems applied for energy systems integration: State-of-the-art applications and trends in microgrids. Appl. Energy 2017, 187, 820-832. [CrossRef]

90. Chalkiadakis, G.; Elkind, E.; Polukarov, M.; Jennings, N.R. The Price of Democracy in Coalition Formation. In Proceedings of the 8th International Conference on Autonomous Agents and Multiagent Systems_Volume 1; International Foundation for Autonomous Agents and Multiagent Systems: Richland, SC, USA,2009; pp. 401-408.

91. Wylie, B. Open Data Endgame: Countering the Digital Consensus; Papers No. 186; Centre for International Governance Innovation: Waterloo, ON, Canadá, 2018; pp. 1-22.

92. Nugent, T.; Upton, D.; Cimpoesu, M. Improving data transparency in clinical trials using blockchain smart contracts. F1000Research 2016, 5. [CrossRef]

93. Chourabi, H.; Nam, T.; Walker, S.; Gil-Garcia, J.R.; Mellouli, S.; Nahon, K.; Pardo, T.A.; Scholl, H.J. Understanding Smart Cities: An Integrative Framework. In Proceedings of the 2012 45th Hawaii International Conference on System Sciences, Maui, HI, USA, 4-7 January 2012; pp. 2289-2297. [CrossRef]

94. Coelho, V.N.; Coelho, I.M.; Oliveira, T.A.; Ochi, L.S. Smart and Digital Cities: From Computational Intelligence to Applied Social Sciences; Springer: Cham, Switzerlands, 2019.

95. Oliveira, T.A.; Coelho, V.N.; Ramalhinho, H.; Oliver, M. Digital Cities and Emerging Technologies. In Smart and Digital Cities: From Computational Intelligence to Applied Social Sciences; Springer: Cham, Switzerlands, 2019; pp. 197-207. [CrossRef]

96. Cruz, S.S.; Pinho, P. Closed Condominiums as Urban Fragments of the Contemporary City. Eur. Plan. Stud. 2009, 17, 1685-1710. [CrossRef]

97. Nelson, R.H. Private Neighborhoods and the Transformation of Local Government; The Urban Institute: Washington, DC, USA, 2005.

98. Glasze, G.; Webster, C.; Frantz, K. Private Cities: Global and Local Perspectives; Routledge: Abingdon, UK, 2006. [CrossRef]

99. Hindman, M. The Myth of Digital Democracy; Princeton University Press: Princeton, NJ, USA, 2009.

100. Colombo, C. Innovación democrática y TIC, ¿hacia una democracia participativa? IDP: Revista De Internet, Derecho Y Política = Revista DÍnternet, Dret I Política; Universitat Oberta de Catalunya: Barcelona, España, 2006; Volume 3, p. 7. [CrossRef]

101. Lemos, A.; Lévy, P. O futuro da Internet: Em direção a uma ciberdemocracia; PAULUS Editora: São Paulo, SP, Brazil, 2010; p. 264.

102. Sayyad, S.; Pawar, M.; Patil, A.; Pathare, V.; Poduval, P.; Sayyad, S.; Pawar, M.; Patil, A.; Pathare, V.; Poduval, P. Features of Blockchain Voting: A Survey. Int. J. 2019, 5, 12-14.

103. Lévy, P. Ciberdemocracia. Tradução de Alexandre Emílio; Instituto Piaget: Lisboa, Portugal, 2002.

104. Coelho, V.N.; Veloso, I.F.O.; Oliveira, T.A.; Coelho, V.N.; Veloso, I.; Veloso, V.M.; Souza, M.J.F.; Filho, A.F.S. A multi-criteria view about judicial and legislative decision making in digital cities and societies. In Proceedings of the XLIX Annual Brazilian Symposium on Operational Research, Blumenau, Brazil, 17-30 August 2017; pp. 3979-3989. (In Portuguese)

105. Allen, D.W.; Lane, A.; Poblet, M. The Governance of Blockchain Dispute Resolution. 2019. Available online: http:/ / dx.doi.org/10.2139/ssrn.3334674 (accessed on 17 January 2020).

106. Martí, J.L. Alguna precisión sobre las nuevas tecnologías y la democracia deliberativa. IDP: Revista De Internet, Derecho Y Política = Revista DÍnternet, Dret I Política; Universitat Oberta de Catalunya: Barcelona, España, 2008; Volume 6, p. 7. [CrossRef]

107. Kies, R. Promises and Limits of Web-Deliberation; Springer: Berlin, Germany, 2010. [CrossRef]

108. Lemos, R. Using the Blockchain for the Public Interest, 2016. Available online: https://medium.com/ positive-returns / using-the-blockchain-for-the-public-interest-2ed1f5114036 (accessed on 12 October 2017).

109. Schneider, F.B. Implementing Fault-tolerant Services Using the State Machine Approach: A Tutorial. ACM Comput. Surv. 1990, 22, 299-319. [CrossRef] 
110. Laufs, J.; Borrion, H.; Bradford, B. Security and the smart city: A systematic review. Sustain. Cities Soc. 2020, 55, 102023. [CrossRef]

111. Ae Chuna, S.; Shulmanb, S.; Sandovalc, R.; Hovyd, E. Government 2.0: Making connections between citizens, data and government. Inf. Polity 2010, 15, 1-9. [CrossRef]

112. Han, B.C. Gesellschaft. 2020. Available online: https://www.perlentaucher.de/9punkt/2020-03-23.html (accessed on 23 March 2020).

113. País, E. The Coronavirus of Today and the World of Tomorrow, by the Phylopher Byung-Chul Han. 2020. Available online: Available online: https:/ / brasil.elpais.com/ideas/2020-03-22/o-coronavirus-de-hoje-e-omundo-de-amanha-segundo-o-filosofo-byung-chul-han.html?rel=mas (accessed on 22th March, 2020).

114. Dudden, A. South Korea Took Rapid, Intrusive Measures Against Covid-19 - and they Worked. 2020. Available online: https:/ / www.theguardian.com/commentisfree/2020/mar/20/south-korea-rapidintrusive-measures-covid-19 (accessed on 23th March 2020).

115. CISCO. From Privacy to Profit: Achieving Positive Returns on Privacy Investments-Data Privacy Benchmark Study; Technical Report, CISCO CYBERSECURITY SERIES; Cisco: San Jose, CA, USA, 2020.

116. Liu, L.; Xu, B. Research on information security technology based on blockchain. In Proceedings of the 2018 IEEE 3rd International Conference on Cloud Computing and Big Data Analysis (ICCCBDA), Chengdu, China, 20-22 April 2018; pp. 380-384. [CrossRef]

117. Luu, L.; Chu, D.H.; Olickel, H.; Saxena, P.; Hobor, A. Making smart contracts smarter. In Proceedings of the 2016 ACM SIGSAC Conference on Computer and Communications Security, Vienna, Austria, 24-28 October 2016; pp. 254-269. [CrossRef]

118. Bouchelaghem, S.; Omar, M. Secure and efficient pseudonymization for privacy-preserving vehicular communications in smart cities. Comput. Electr. Eng. 2020, 82, 106557. [CrossRef]

119. SueNEO. Design of AthenaID. 2020. Available online: https://github.com/neo-project/neo/issues/1306 (accessed on 22 February 2020).

120. lllwvlvwlll. [NeoID] Design of Moonlight. 2020. Available online: https://github.com/neo-project/neo/ issues /1313 (accessed on on 22 February 2020).

121. SueNEO. [NeoID] Design, Discussion and Implementation. 2020. Available online: https://github.com/ neo-project/neo/issues/1304 (accessed on 22 February 2020).

122. Caragliu, A.; Bo, C.F.D. Smart innovative cities: The impact of Smart City policies on urban innovation. Technol. Forecast. Soc. Chang. 2019, 142, 373-383. doi:10.1016/j.techfore.2018.07.022. [CrossRef]

123. Geissinger, A.; Laurell, C.; Sandström, C.; Eriksson, K.; Nykvist, R. Digital entrepreneurship and field conditions for institutional change-Investigating the enabling role of cities. Technol. Forecast. Soc. Chang. 2019, 146, 877-886. [CrossRef]

124. Appio, F.P.; Lima, M.; Paroutis, S. Understanding Smart Cities: Innovation ecosystems, technological advancements, and societal challenges. Technol. Forecast. Soc. Chang. 2019, 142, 1-14. [CrossRef]

125. Räisänen, J.; Tuovinen, T. Digital innovations in rural micro-enterprises. J. Rural Stud. 2020, 73, 56-67. [CrossRef]

126. Lee, J.Y. A decentralized token economy: How blockchain and cryptocurrency can revolutionize business. Bus. Horizons 2019, 62, 773-784. [CrossRef]

127. Lindgren, I.; Østergaard Madsen, C.; Hofmann, S.; Melin, U. Close encounters of the digital kind: A research agenda for the digitalization of public services. Gov. Inf. Q. 2019, 36, 427 - 436. [CrossRef]

128. Coelho, V.N.; Coelho, I.M.; A.Oliveira, T.; Ochi, L.S. (Eds.) Smart and Digital Cities; Springer: Cham, Switzerlands, 2019. [CrossRef]

(C) 2020 by the authors. Licensee MDPI, Basel, Switzerland. This article is an open access article distributed under the terms and conditions of the Creative Commons Attribution (CC BY) license (http:/ / creativecommons.org/licenses/by/4.0/). 